\title{
Endoscopic therapy of appendicular bleeding complicated by shock
}
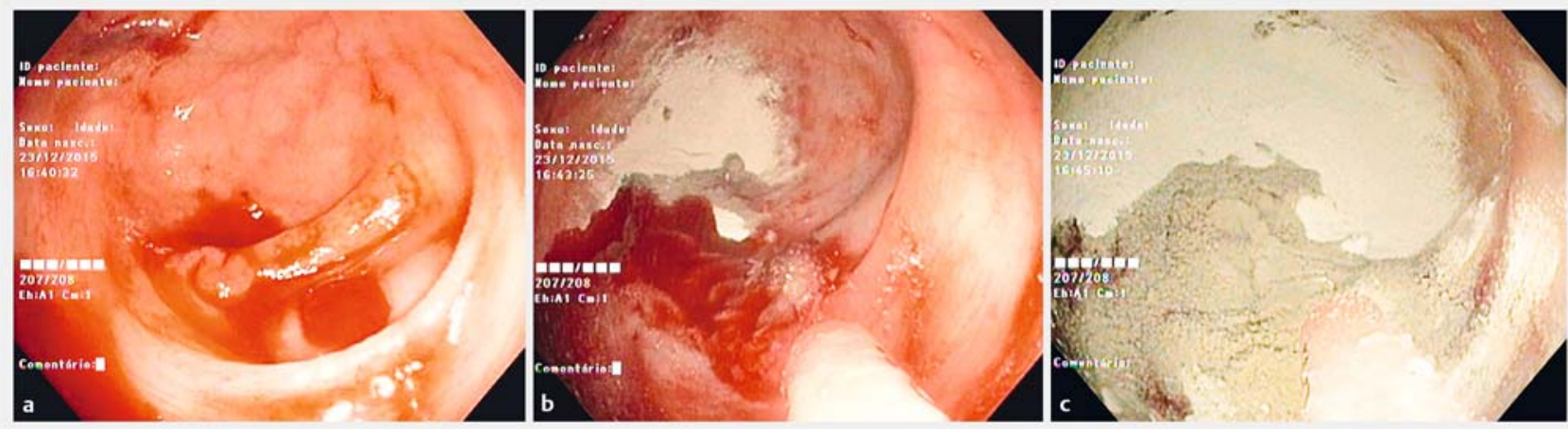

Fig. 1 Endoscopic views showing: a active bleeding from the ileocecal appendix; $\mathbf{b}$ continued bleeding from the appendix after an initial burst of the hemostatic spray; $\mathbf{c}$ sustained hemostasis after the application of several bursts of the hemostatic spray.

A 57-year-old man, who was receiving antiplatelet therapy with acetylsalicylic acid for ischemic heart disease and had a recently diagnosed stage IV pulmonary adenocarcinoma (with liver and bone metastases), presented with hemorrhagic shock due to painless hematochezia. Total colonoscopy revealed active bleeding from the ileocecal appendix ( Fig.1a). Initially epinephrine was injected at the appendicular base, but the bleeding was ongoing. Endoscopic therapy with hemostatic spray (Hemospray; Cook Medical, Winston-Salem, North Carolina, USA) was tried, with the achievement of immediate hemostasis ( $\triangleright$ Fig.1b,c; \Video 1). No recurrent bleeding was reported during the follow-up period (3 months).

Appendicular bleeding is an exceptional cause of lower gastrointestinal hemorrhage that can arise from various etiologies, including granulomatous appendicitis, inflammatory bowel disease, tuberculosis, benign erosions and ulcers, neoplastic disease, and aorto-appendicular fistula [1,2]. Because of the difficult approach to the bleeding vessels endoscopically, emergent surgery has been necessary in most reported cases [3]. Hemospray is a hemostatic powder that forms a mechanical barrier when it comes into contact with an active bleeding site. Preliminary data have shown that it can be effective in the management of lower gastrointestinal bleeding [4].

In the case presented, because of the patient's high surgical risk and considering the potential for the development of severe appendicitis after clip placement due to persistent blockage of the appendiceal lumen, the application of hemostatic spray was the best therapeutic option. Because of the dismal prognosis of the patient's underlying neoplastic disease, no further intervention was performed, apart from stopping the antiplatelet therapy. To our knowledge, this is the first reported case of active bleeding from the ileocecal appendix that was successfully controlled with the application of hemostatic spray.

Endoscopy_UCTN_Code_TTT_1AQ_2AZ

\section{Competing interests}

None

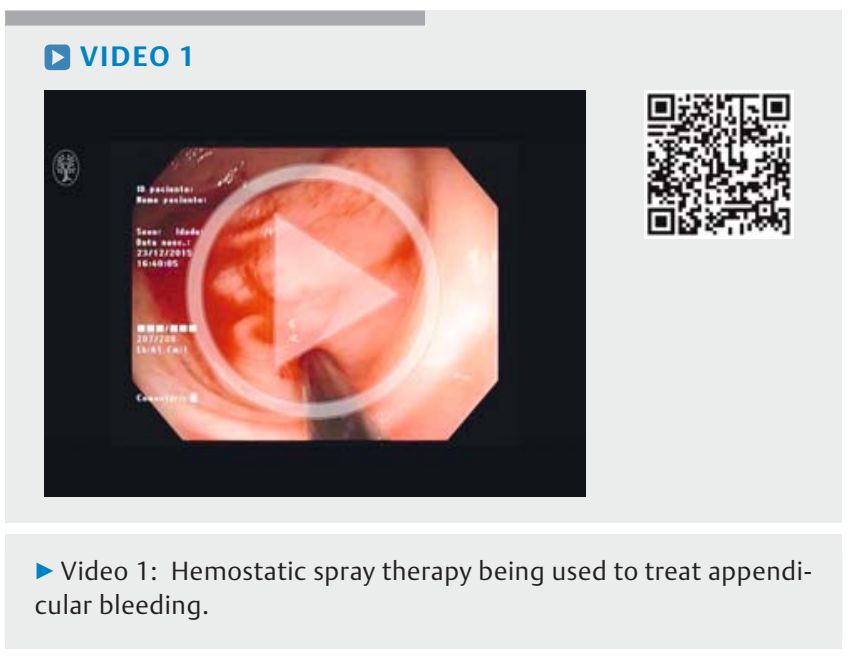


José Rodrigues, Joana Carmo, Liliana Carvalho, Miguel Bispo, Pedro Barreiro,

\section{Cristina Chagas}

Serviço de Gastrenterologia, Centro Hospitalar de Lisboa Ocidental, Hospital de Egas Moniz, Lisboa, Portugal

\section{Corresponding author}

José Rodrigues, MD

Serviço de Gastrenterologia, Centro Hospitalar de Lisboa Ocidental - Hospital de Egas Moniz , Rua da Junqueira 126, 1349-019 Lisboa, Portugal

jp.azevedo.rodrigues@gmail.com

\section{References}

[1] Magaz-Martínes M, Martín-Lopez ], De-laRevilla-Negro J et al. Appendicular bleeding: an excepcional cause of lower haemorrhage. Rev Esp Enferm Dig 2016; 108: 437 - 439

[2] Konno Y, Fujiya M, Tanaka K et al. A therapeutic barium enema is a practical option to control bleeding from the appendix. BMC Gastroenterol 2013; 13: 152

[3] Kim KJ, Moon W, Park MI et al. Gastrointestinal stromal tumor of appendix incidentally diagnosed by appendiceal hemorrhage. World J Gastroenterol 2007; 13: 3265 - 3267

[4] Holster L, Brullet E, Kuipers E et al. Hemospray treatment is effective for lower gastrointestinal bleeding. Endoscopy 2014; 46: $75-78$

\section{Bibliography}

DOI http://dx.doi.org/10.1055/s-0043-100213 Endoscopy 2017; 49: E90-E91

(c) Georg Thieme Verlag KG

Stuttgart · New York

ISSN 0013-726X 